DOI: 10.4274/tpa.46.21

\title{
Ergen sağlğının sürdürülme ve geliştirilmesinde hemşirenin rolü
}

\section{The role of the nurse on health promotion and health maintenance of adolescents}

\author{
Gülümser Dolgun, Sevil İnal, Figen Uğurlu \\ istanbul Üniversitesi Bakırköy Sağık Yüksekokulu, İstanbul, Türkiye
}

\begin{abstract}
Özet
Ergenlerin sağlığının sürdürülmesi ve geliştirilmesinde hemşireler vazgeçilmez bir role sahiptir. Hemşireler, ergene uygun yaklaşımın temel ilkelerini bilmeli, sağlığın sürdürülmesi ve geliştirilmesinde ergen ve ailesine rehberlik edebilmelidir. Bu makalede, ergen ve ailesinin genel gözlem ilkeleri, ergenin ana sağılk konularına uygun hemşirelik yaklaşımı, hemşirenin ergenin beslenmesi, fiziksel etkinliği, akıl sağlığı ve büyüme gelişmesi gibi konularda topladığı verileri nasıl değerlendireceği, ergen ve ailesiyle kurulacak iletişimin özellikleri, ergenin sağlığını geliştirmeye yönelik fiziksel etkinliğin çocuk ve ailenin yaşamıyla bütünleştirilmesi, hastalık ve kazalardan korunmaya yönelik hemşirelik yaklaşımı ele alınmıştır. (Türk Ped Arş 2011; 46 Özel Sayl: 4-8)
\end{abstract}

Anahtar sözcükler: Sağlığın sürdürülmesi, sağlığın geliştirilmesi, ergen, hemşirelik bakımı

\section{Summary}

Nurses have an indispensable role in maintenance and promotion of adolescens' health. Nurses must know the basic principles of appropriate approach to adolescents, should be able to guide the adolescent and family in the promotion and maintenance of health. In this article, general observation principles of adolescent and family, the appropriate nursing approach to the major adolescent health issues, how to evaluate gathered data about adolescent's such as nutrition, physical activity, mental health and, development and growth, the properties of therapeutic communication with adolescent and family, physical activity to be integrated into the life of the adolescent and family, nursing approach to illness and accident prevention has been handled. (Turk Arch Ped 2011; 46 Suppl: 4-8)

Key words: Health maintenance, health promotion, adolescent, nursing care

\section{Giriş}

Sağlığın sürdürülmesi ve geliştirilmesi kavramları hemşirelik bakımının vazgeçilmez bileşenleridir. Sağlığın geliştirilmesi bireylere onların sağlık potansiyellerini maksimum düzeye çıkaracak bir yaşam biçimi seçmelerine yardım edecek tutum ve becerileri kazandırmayı amaçlar. Aile ve toplumun güçlendirilmesine önemli katkılar sağlayan hemşirelik, bireyi yaşamının bütün yönleriyle ele alan holistik (bütüncü) bir meslektir. Bu yüzden hemşireler sağlığın sürdürülmesine ve geliştirilmesine yönelik etkinliklerde eşsiz ve vazgeçilmez bir role sahiptir (1). Çocuk sağlığının geliştirilmesi, sağlı̆ı̆ı değerini erken yaşlarda öğrenen bireyin, sağlıklı yaşam biçimini benimseyeceği görüşüne temellenmektedir (2). Çocukluğun önemli bir evresi olan ergenlik evresinde sağlığın sürdürülmesi ve geliştirilmesi bu nedenle büyük önem taşımaktadır. Ergenin sağıı bakımının karşılanması sırasında hemşireler, sağlık ocakları, ana çocuk sağlığı merkezleri, hastaneler, rehabilitasyon merkezleri ve okullar gibi pek çok alanda diğer sağlık profesyonelleri ile işbirliği yaparak ergen sağlığın sürdürülmesi ve geliştirilmesi için çalışmalıdır (3-6). 


\section{Ergenin genel değerlendirmesi}

Ergenlik evresi, başlangıç ve bitiş sürelerinin belirlenmesinde olduğu kadar normal ve anormalliğinin belirlenmesinde de güçlük çekilen bir dönemdir. Ergene sağlık hizmeti verecek olan hemşireler, ergenlerin büyüme gelişmesini, bireysel farklııkların normal ve anormal sınırlarını, ergenin sağlık risklerini ve bunların etkilerini bilmelidir. Hemşire ergene sağlık hizmeti verirken, ergene sunulan sağlığı sürdürmeye ve geliștirmeye yönelik sağlık hizmetinin amaç ve yararları hakkında ergene ve ailesine bilgi vermeli, sağlığı sürdürme ve geliştirmeye yönelik girişimlere ergen ve aileyi etkin olarak katmalıdır. Ergene verilen sağlığı sürdürmeye ve geliştirmeye yönelik eğitim ve danışmanlık hizmetleri, büyüme gelişmesi ve psikososyal uyumu tamamlanıncaya kadar devam etmelidir (7-10).

Hemșireler sağlık izlemi sırasında, ergenin genel değerlendirmesini yapmall, öykü almalı, fiziksel ölçümlerini alarak sağlıklı büyüyüp büyümediğini değerlendirmeli, ergene aldığı fiziksel ölçümlerle ilgili bilgi vererek ergenin sorularını yanıtlamalı ve endişelerini gidermelidir $(3,11,12)$.

Öykü alma: Öykü alma, sağlık sorunlarının ortaya çıkarılmasında son derece önemlidir. Ergen hakkındaki bilgilerin hepsi kendisinden alınmalı, aileye de eksik bilgileri tamamlama fırsatı verilmelidir. Hemşireler ergenden bilgi alırken, soruları açık, anlaşıır bir dille sormalıdır. Ergenin mahremiyeti ve gizlilik gereksinimi ile ebeveynlerle ilișkisi arasındaki doğru dengeyi bulabilmek çok önemlidir. İlk görüşmede ergene neden kişisel konularla ilgili sorular sorulacağı anlatılmalıdır. Ergene soruların soruluş amacı açıklandıktan sonra, isterse yanıtlamayabileceği belirtilmelidir. Sağlığı sürdürme ve geliștirmeye yönelik ergen değerlendirmesinde, başlangıçta arkadaşlar, hobiler gibi ergenin konuşmaktan hoşlandığı konularda sorular sorularak sohbet başlatılmalı ve ergenin bir süre konuşarak rahatlamasına olanak sağlanmalıdır (13-15).

Öyküye varsa, sağlık sorununun değerlenmesi ile başlanmalı, öz geçmiş, gebelik ve doğum öyküsü, çocukluk çağında sık karşılaşılan hastalıklar, hastaneye yatış ya da ameliyat öyküsü, bağışıklama ve büyüme ve gelişme hakkında bilgi alınmalıdır. Aile öyküsünde ebeveynlerin yașları, sağlık durumları, kardeşlerin yaşları ve sağlık durumları sorgulanmalıdır. Ailede kalıtsal hastalıklar ve bulaşıcı hastalıkların varlığı araştııımalıdır. Ergenin nerede ve kimlerle yaşadığı, ailesi ve kardeşleri ile ilişkileri hakkında bilgi alınmalıdır. Ergenin duyarlı olduğu konular sona bırakılmalıdır. Okul yaşantısı, arkadaş ve öğretmen ilişkileri hakkında bilgi alınmalı ve gelecekle ilgili düşünceleri sorulmalıdır. Ergenin bir iş yerinde çalışıyorsa çalışma koşulları ve memnuniyeti değerlendirilmelidir (14-15).

Madde kullandığını belirten ergen, kullandığı ortam, kullanma süresi, sıklığı ve miktarı açısından sorgulanmalı ve madde bağımlıı̆ı gelişip gelişmediği değerlendirilmelidir. Ergenler depresyon ve intihar hakkında konuşmakta güçlük çekebilirler. Hemşire ergenle bu konuları tartışmadan önce onun aile içi ilişkileri, okul yaşantısı, arkadaş ilişkileri, boş zaman etkinlikleri, madde kullanımı ve cinsel deneyimleri hakkında önemli bilgiler toplamış, dostça bir ilişki kurmuş ve ergenin güvenini kazanmış olmalıdır. Ergene intihar düşüncesi, planı ve girişimi ile ilgili sorular sorulmalıdır. Ayrıca evden kaçma, ciddi aile içi çatışmalar, okul başarısında düşme, arkadaşı olmama, madde kullanımı, erken yaşta cinsel ilişkiye girme ve intihar girişimi gibi riskli sağık davranışları olduğu saptanan ergenler cinsel ve fiziksel istismar açısından mutlaka değerlendirilmelidirler $(3,16)$.

Fiziksel değerlendirme: Ergenin fiziksel değerlendirmesi antropometrik ölçümler, cinsel gelişimin ve sistemlerin sorgulanmasını içerir. Boy ve ağırlık ölçümü, beden kitle indeksinin saptanması, kan basıncı ölçümü, görme kusurları, guatr açısından tiroid bezinin, skolyoz açısından omurganın, kızlarda meme hastalıkları açısından memelerin ve erkeklerde cinsel yolla bulaşan hastalıklar ve tümörler açısından testislerin değerlendirilmesi fiziksel değerlendirmenin bir parçası olmalıdır (17).

Fiziksel değerlendirme başlanmadan önce, gerekçesi ve detayları ergene anlatımalı, değerlendirme sırasında merak ettiği konularda soru sorabileceği söylenmeli, ergenin fiziksel değerlendirmeye etkin olarak katılması sağlanmalıdır. Fiziksel değerlendirme tamamlanmadan, ergen soru soruyormuşçasına ne yapıldığı ve değerlendirmenin sonuçları hakkında bilgi verilmelidir $(16,17)$.

\section{Sağlığı geliştirmeye yönelik girişimler}

Beslenme: Ergenlik evresindeki hızı büyüme, enerji ve besin öğelerine olan gereksinimin artmasına neden olmaktadır. Ergen için hızı büyüme ve gelişmeyi sürdürmesini sağlayacak, yüksek kalorili, yağı, şekeri ve sodyum içeriği az, dengeli bir beslenme rejimi sağlanmalıdır. Besin ve enerji gereksinimi her ergen için ayrı değerlendirilmelidir. Çünkü bu yaş döneminde ergenlerin büyüme ve gelişimsel özellikleri, etkinlik düzeyleri birbirinden çok farklı olabilir. Ergenin aileden bağımsız davranma eğilimi nedeniyle, yiyecek alışkanlıkları ve seçiminde ailenin etkisi azalır. Öğün atlama, öğün aralarında atıştırma (besin değeri düşük, bol kalori ve yağ içeren yiyecekler yeme), ev dışında yemek yeme ve fast-food türü besinleri tüketme ergenlerde en sık görülen sağlıksız beslenme davranışlarıdır. Ergende sağlıklı beslenme biçiminin geliştirilmesi hemşirenin en önemli sorumluluklarından biridir. Hemşire kilo vermek isteyen şişman ergen için, sağlıklı beslenme programı oluştururken, var olan beslenme düzeni ve içeriğini değerlendirirken ergeni de işin içine katmalıdır. Ergenin, gerçekçi bir hedef belirlerken ve sağlıklı bir beslenme rejimi oluştururken hem ebeveyninin hem de hemşirenin desteğine gereksinim duyacağı unutulmamalıdır $(3,5,16,18,19)$.

Fiziksel etkinlik: Ergenlik evresi, anatomik ve fizyolojik değişim ve gelişimlerinin maksimum düzeyde olduğu, 
bazen bu değişikliklere uyumda sorunların yaşandığı bir evredir. Bu dönemde büyümenin devam etmesi nedeniyle uygun fiziksel etkinliklerin seçilmesi önemlidir. Fiziksel etkinlik belirlenirken, ergenin fiziksel yeterliliğinin bilinmesi ve gereksiz zorlamalardan kaçınılması önemlidir. Son yıllarda fiziksel etkinliğin azalmasına bağlı olarak çocukluk çağı ve ergenlik evresinde șişmanlık önemli bir sağlık sorunu haline gelmiştir. Ergenlik evresindeki şişmanlık, yetişkin evresindeki şişmanlığın bir habercisidir ve sonraki yıllarda kalp ve damar hastalıkları riskini arttırmaktadır. Şişmanlığın önlenmesinde en etkili yöntem sağlıklı beslenme ile birlikte egzersiz yapılmasıdır. Yürüme, koşma, yüzme, basketbol ve voleybol ergenlik evresinde yapılacak sporlara örnek olarak verilebilir. Bu dönemde ergen spora yönlendirirken mutlaka fiziksel uygunluğu ve gelişim düzeyi değerlendirilmeli ve ergenin yapmak istediği sporlar göz önünde bulundurulmalıdır. Hemşire ergenin yaşına ve gelişim düzeyine uygun fiziksel etkinliğin planlanmasında ergen ve ailesine rehberlik etmelidir $(3,5,18,20,21)$.

Ağız sağlığı: Ergenlerde gingivit, diş çürükleri ortodontik sorunlar gibi ağız ve diş sağlığı sorunları görülebilmektedir. Hemşirelik girişimleri ağız ve diş sağlığını koruma ve geliştirmeye yönelik ergenin gerekli bilgi ve beceriyi kazanmasına ve kendi ağız bakımını gerçekleștirme sorumluluğunu almasına odaklanmalıdır. Ergen günde en az 2 kez düzenli diş firçalamaya ve günde $1 \mathrm{kez}$ diș ipi kullanmaya, kalsiyum içeren süt, peynir, yoğurt gibi gıdaları yeterli miktarda tüketmeye, basit şeker tüketimini sınırlandırma gibi ağız sağlığını koruyucu tedbirler almaya teşvik edilmelidir. Hemşire ayrıca ortodontik sorunu olan ergenlerin diş teli uygulaması gibi tedavilere uyumu konusunda ebeveyni tarafından desteklenmesini sağlamalıdır $(3,5,14)$.

Akıl sağlı̆ı̆: Ergen için beden imgesi ve akranları arasında görünümü son derece önemlidir. Beden imgesiyle ilgili endişeler özellikle kız ergenlerde daha sıklıkla görülmektedir. Bu yaşta beden imgesinin çok önemli olması ve zayıf bir bedene sahip olma arzusu nedeni ile sağlıksı beslenme davranışları görülebilir. Bu nedenle bu dönemde anoreksia nervoza, bulimia gibi beslenme sorunları daha sık görülür.

Özellikle bu dönemde fiziksel olarak güçlü ve çabuk gelişen ergenler grupta liderliği ele alır ve kabul görür. Geç gelișen ergenlerin yașıtları arasında çocuk olarak algılanması üzüntü yaratabilir. Hemşire, ergenin büyüme ve gelişmesi ile ilgili kaygılarını dinlemeli ve büyüme gelişmesini onunda anlayabileceği bir şekilde değerlendirerek, normal büyüme ve gelişme gösterdiğini açıkça ifade etmelidir $(3,5,14)$.

ilişkiler: Ergenin sıkıntılarından, duygusal dalgalanmalarından tüm aile bireyleri etkilenir. Ergen özgür olmak isteği ile ebeveynlerinin kendisiyle yeterince ilgilenmedikleri suçlamaları arasında gidip gelirken, anne ve baba ise çocuklarını serbest bırakmak ve korumak arasında gidip gelir. Bu dönemde aile sınırlarının bir miktar esneklik kazanması, ergenin dışarıyla ilişkilerinin artışına ve gidiş gelişlerine izin verilmesi, ergen için kuralların bir miktar esnetilmesi, özerkliğini arttıracak biçimde fiziksel ve duygusal düzenlemelerin yapılması gerekir.

Ergenlerin sağlığının korunması ve geliştirilmesinde ailenin önemi oldukça büyüktür. Ergenler ebeveynlerinin davranışlarını örnek alarak sağlıklı davranışlar geliştirebilirler. Bu nedenle ebeveynler davranıșlarının ergenler üzerindeki etkisi hakkında bilgilendirilmelidirler. Bu dönemde ergenlerin aileleriyle ve çevreleriyle çatışmalar yaşayacakları oldukça zor ve riskli bir dönemdir. Ergenlerin yetișkinliğe sağlıklı bir geçiş yapabilmesi için, ailelerin okul ve toplumla iş birliği içerisinde ergene doğru yaklaşımda bulunması gerekmektedir. Ergenle ilişkilerde, sevgi, güven ve saygı dolu bir aile ortamı sunmak, yaşlarına uygun bağımsızlıklar vermek ve özgürlükler tanımak gibi temel ilkelere uyulması gerektiği ailelere anlatımalıdır $(3,5,14)$.

\section{Hastalıkları önlemeye yönelik girişimler}

Hemşireler ergenlere sağlıklı beslenme ve egzersizin yararlarının yanı sıra, sorumlu cinsel davranışlar, kondom kullanımı ve cinsel yolla bulaşan hastalıklardan korunma ve gebeliklerin önlenmesi konularında gelişim düzeylerine uygun bilgiler vermelidir. Ayrıca sigara, alkol ve diğer maddelerin kullanımına, kazaların ve yaralanmaların önlenmesine yönelik gerekli rehberlik ve danışmanlık sağlanmalıdır. Alkollüyken araba kullanmanın sakıncaları, emniyet kemeri kullanımının önemi, sakatlıkları ve yaralanmaları önleyici tedbirler almalarının yararları anlatımalıdır $(7,11,13)$.

Ergenlerin yılda bir kez kan basıncı ölçülmelidir. Bu ölçümde kan basıncı 90. persantilde ya da üzerinde ise, bir ay içerisinde 3 farklı zamanda tekrar ölçülerek ilk değer doğrulanmalıdır. Kan basıncı 90-95. persantil arasında ise şişmanlık açısından değerlendirilmeli ve kan basıncı ölçümü 6 ayda bir tekrarlanmalıdır. Kan basıncı 95. persantilin üzerinde ise, sağlığı kapsamlı olarak değerlendirilmeli ve gerekli tedavisinin yapılması için ilgili birimlere yönlendirilmelidir $(3,5,14)$.

Ergenlerin pek çok konuda bilgilerinin yetersiz olmasının, riskli sağlık davranıșlarını daha fazla benimsemelerine neden olduğu düşünülmektedir. Gençlerin "kendilerini riskli grupta görmemelerinin" riskli sağlık davranışlarının ortaya çıkmasında bir başka etkili etken olduğu bilinmektedir (22).

Ergenlik evresinde kazanılan riskli sağlık davranışları, erişkin dönemde mortalite ve morbidite oranlarında ciddi artışlara neden olmaktadır. Bu nedenle ergenler sigara, alkol ve uyuşturucu maddelerin kullanımı açısından değerlendirilmelidir. Herhangi birini kullandığı belirlenen ergenler, aile öyküsü maddeyi kullandığı ortam, kullanma sıklığı ve diğer maddeleri kullanıp kullanmadığı, cinsel davranışları, fiziksel sağlığı, psikososyal durumu ve okul sorunları açısından değerlendirilmelidir. Gerekirse uygun tedavi olanaklarının bulunduğu bir merkeze yönlendirilmelidir (23-26). 
Okul başarısında düşme, fiziksel ya da cinsel istismar, alkol ve madde kullanımı, önceden intihar planları ya da girişimi öyküsü gibi risk etkenleri olan ergenler depresyon ve intihar riski açısından değerlendirilmelidir. Depresyon belirtileri ya da intihar riski olan ergenler psikiyatrik tedavi için gerekli birimlere yönlendirilmelidir.

Ergenlerin sağlık izlemi sırasında duygusal, fiziksel ve cinsel istismar açısından değerlendirilmesi önemlidir. İstismar saptanan ergenler istismarın fiziksel, duygusal ve psikososyal etkileri açısından değerlendirilmeli ve gerekirse psikiyatrik yardım alması sağlanmalıdır. Ayrıca istismar olayı adli makamlara da bildirilmelidir (23-26).

Ergenler öğrenme güçlüğü ve okul sorunları açısından değerlendirilmelidir. Tekrarlayan okul kırma öyküsü, okul başarısızlığı ya da okul başarısında düşüş olan ergenler öğrenme güçlüğü, dikkat eksikliği hiperaktivite bozukluğu, fiziksel sorunlar, cinsel istismar, aile disfonksiyonu, mental hastalıklar, alkol ya da diğer maddelerin kullanımı açısından değerlendirilmelidirler.

Ergene verilmesi gereken bağışıklama hizmetleri ülkemizde ergenlik çağında Sağılı Bakanlığı'nın Ulusal aşı takvimine uygun olarak erişkin tipi difteri ve tetanoz aşısının ilköğretim son sınıfta yapılması şeklindedir. CDS (Center For Diseasee Control) ergenlere daha önce yapılmamışsa kızamık, kızamıkçık, kabakulak aşısı yapılmasını, hastalığı geçirmemişse 2. doz aşı uygulanmasını önermektedir. Hepatit B aşısı yapılmayan ergenlerin Hepatit B'ye karşı aşılanması önerilmektedir. Suçiçeği geçirme öyküsü olmayan ergenler suçiçeğine karşı aşılanmalıdır. Suçiçeği aşısı 13 yaşından sonra en az bir ay arayla 2 doz uygulanmalıdır. Hemşireler ergenlik evresinde uygulanması gereken aşıları, uygulama yollarıı, oluşabilecek yan etkileri bilmeli, ergen ve ailesine bağıșıklama konusunda uygun danışmanlık hizmeti verebilmelidir (23-27).

Ergenlik çağının en önemli özelliği; mortalite ve morbidite nedeni olabilecek erken gebelik, kazalar ve yaralanmalar, madde bağımlıı̆ı gibi daha çok davranışlarla ilgili sorunların yaşanmasıdır. Ergenlerde yeni şeyleri deneme merakı, yetişkinleri model alma ve arkadaş grubu tarafından kabul edilme gibi nedenlerin riskli sağlık davranışlarına eğilimi arttırdığı unutulmamalıdır. Hemșire ergeni ve ebeveyni bu döneme özgü kaza riskleri konusunda bilgilendirmeli ve alınması gereken önlemler konusunda rehberlik etmelidir $(3,5,14)$.

Hasta ergene yaklaşım: Hastalıkların ergenler üzerindeki etkileri kişinin gelişim evresine göre farklılıklar göstermektedir. Erken ergenlik evresinde hastalığın etkileri daha çok fiziksel gelişim ve beden imgesi ile ilgilidir. Ergen için fizik görünümünü değiştiren ya da işlev kaybına neden olan hastalıklar, bu dönemin özellikleriyle bağdaşmadığı için son derece örseleyicidir. Orta ergenlik evresi ise bağımsız var olma çabaları ve sosyal varlık kaygısı ile karakterizedir. Bağımsızlığını yitirmesi, yatağa ya da hastaneye bağımlı kalması ergenin gerginlik, öfke duymasına, içe kapanmasına, tedaviyi reddetmesine ya da tam tersi olarak hastalı̆̆ı önemsememesine neden olabilir. Bağımsızlık gereksinimi, kimlik arayışı, çeşitli fiziksel ve psikolojik değişiklikler, hastaneye yatma ve onun neden olduğu kısıtlııklar kontrol kaybına neden olduğundan, hastalıkla baş etmeyi güçleştirir. Ayrıca arkadaşlarından ayrı kalmasının yanı sıra beden imgesindeki değişiklikler, diğer kişilerin kendisini reddedeceği korkusuna, anksiyeteye ve kendine güvenini yitirmesine neden olur. Geç ergenlik devresi ileriye, geleceğe yönelik planlara ve kimlik arayışlarına odaklı bir dönemdir. Bu evrede kronik hastalık oluşumu, mesleki ve akademik planlarla ilgili, aile kurma ve ebeveynlik planları ile ilgili kaygılara yol açar. Ayrıca ergenin yeni oluşan kimliğine ve gelecek planlarına zarar verici olarak algılanabilir $(3,28)$.

Özellikle ergenlik döneminde, bireyler pek çok fizyolojik ve psikolojik değişimlerle karşı karşıyadır. Bu durumlara kronik hastalığın eklenmesi onların sosyal ve psikolojik gelişimlerini engelleyebilmekte ya da çeşitli sorunların ortaya çıkmasına neden olabilmektedir. Hastaneye yatan çocukların bazı kişilik özelliklerinin gelişiminde aksaklıklar olabilir. Ergenler yaşamı tehdit eden hastalıkların risklerini yetişkinler kadar anlayabilseler de tıbbi ekiple tam uyum içinde yaşam değişikliklerini kabul etmeleri beklenmemelidir. Hemşire öncelikle ergenin hastalığı ve beden işlevlerine etkisi konusunda bilgi düzeyini belirlemeli, korku ve endişelerinin farkına varmalıdır. Ergenin ameliyattan sonra bedeninde şekil bozukluğu kalıp kalmayacağı konusunda endişeleri olabilir. Görünümünü düzeltmek amacıyla yapılabilecek plastik cerrahi ve protez uygulamaları konusunda bilgi verilmesi ve benzer durumla başarılı şekilde baş etmiş olan diğer ergenlerle tanıştırılması yararlı olabilir. Ergenin, hastane ortamında diğer akranları ile iletişime girmesine, aynı yaştaki kişilerle odasını paylaşmasına, toplantılar düzenlenmesine, onların hastaneye yatmaya ilişkin sorunlarını paylaşmasına fırsatlar yaratmak için sosyal etkileşimler düzenlenmelidir. Ayrıca ergenin gizlilik gereksinimine saygı gösterilmesi, kendi bakımını üstlenmesi, kendi bakımına ilişkin kararlara katılması ve böylelikle yaşamı üzerinde bir miktar kontrol sahibi olması sağlanmalıdır $(8,14,28)$.

Hemşirenin ergenin hastalığa uyumunda aile yapısının ve desteğinin de çok önemli olduğunu bilmesi ve aileye de eğitim vermesi gereklidir. Ailelerin aşırı koruyucu, aşırı kaygılı, mükemmelliyetci, denetleyici ya da tam tersi aşırı hoşgörülü, teslimiyetçi, ilgisiz ve reddedici olmaları ergenin hastalığa uyumunu zorlaştıracaktır. İlişkilerde dengeli, duyguların serbestçe ifadesine izin veren, çatışmaların az, işbirliğinin fazla olduğu bir ailede ergenin hastalı̆̆a uyumu en iyi olmaktadır. Ayrıca ergenin güven duydukları hekim ve hemşire ile iletişimlerini sürdürmek istemeleri de desteklenmelidir. Hemşire, ergenle çalışmada, açık ve esnek olmalı, olaylara mizah katabilmeli ve ergenin ne söylediğini dinlemeye istekli olmalıdır $(8,14,28)$. 


\section{Kaynaklar}

1. Ocakçı A. Sağlığın korunma ve geliştirilmesinde hemşirelik hizmetlerinin rolü. 2002. (Full Text)

2. Savașer S. Çocuk sağlığının korunması ve geliștirilmesinde hemşirenin rolü. 22. Pediatri Günleri ve 2. Pediatri Hemşireliği Günleri Program ve Özet Kitabı. 18-21 Nisan 2000: İstanbul, 362-70.

3. Ball JW, Bindler RC. Child Health Nursing, Partnering with Children and Families. New Jersey: Pearson Education, 2006: 479-98.

4. Hokenberry MJ. Wong's Essentials of Pediatric Nursing, Seventh Edition, Philadelphia: Elsevier Mosby, 2005: 421-63.

5. Neinstein LS. Adolescent Health Care, A Practical Guide, Fifth Edition. Philadelphia: Lippincott Williams \& Wilkins, 2008: 332-451.

6. Adelman W, Ellen J. (Çev: Derman O). Adolesan. İçinde: Rudolph Am, Kamei RK, Overby KJ (Çev: Yurdakök M). Rudolph's Fundamentals of Pediatrics. Ankara: Güneş kitabevi, 2003: 70-110.

7. Adolesan Sağlığı ve Gelișimi Programı Rehber Kitabı. TC. Sağlık Bakanlığı AÇS/AP Genel Müdürlüğü. Ankara: Unicef, 2002.

8. WHO (2008) Child and Adolescent Health and Development. http:// www.who.int/en/.(erișim:09.09.2010). (Full Text)

9. Bernat DH, Resnick MD. Healthy youth development: Science and strategies. J Public Health Manag Pract 2006; 10-6.

10. Johnson RL. Gender differences in healthpromoting lifestyles of African Americans. Public Health Nursing 2005; 22: 130-7. (Abstract) / (Full Text) / (PDF)

11. Ercan O. Adolesana yaklașım. İçinde: Ercan O ed (s). Adolesan Sağlığı. iÜ Cerrahpaşa Tıp Fakültesi Sürekli Tıp Eğitimi Etkinlikleri, Sempozyum Dizisi No: 43, İstanbul; Kaya Basım, 2005: 23-7.

12. Whetsell-Velasco M, Coffin DA, Lizardo LMü, et al. Pediatric Nursing, America. McGraw-Hill Companies 2000: 100-18.

13. Alikașifoğlu M. Adolesana yaklașım. Türk Pediatri Arşivi 2005; 40: 191-8. (PDF)

14. Wong DL, Wilson D. Nursing Care of Infants and Children. Fifth Edition. Philadelphia: Mosby, 1995: 825-94.

15. Yavuz R. Birinci basamakta adolesan sağlığına biyopsikososyal yaklaşım. Aile Hekimliği Dergisi 2009; 3: 28-32. (Full Text)
16. Yıldız S. Okul çocukluğu ve adolesan döneminde sağlığın korunması, geliștirilmesi ve sürdürülmesi, 49. Milli Pediatri Kongresi ve 5. Milli Çocuk Hemşireliği Kongresi Özet Kitabı: İstanbul, 2005; 428-9.

17. Ercan O. Adolesanın fiziksel gelişimi. İçinde: Ercan O ed (s). Adolesan Sağlığı II. IÜ Cerrahpaşa Tıp Fakültesi Sürekli Tıp Eğitimi Etkinlikleri, Sempozyum Dizisi No: 63 İstanbul: Aksu Basım Yayın, 2008: 13-8.

18. İnal S. Spor yapan çocukta beslenme. IX. Uluslararası Katıımlı Beslenme ve Metabolizma Kongresi Özet Kitabı: İstanbul, 2007; 250-1.

19. Erkan T. Ergenlerde beslenme. İçinde: Ercan O ed (s). Adolesan Sağlığı II. iÜ Cerrahpaşa Tıp Fakültesi Sürekli Tıp Eğitimi Etkinlikleri, Sempozyum Dizisi No: 63 İstanbul: Aksu Basım Yayın, 2008: 73-9.

20. Berberoğlu M. Adolesanlarda obezite. İçinde: Ercan O ed (s). Adolesan Sağlığı II. iÜ Cerrahpaşa Tıp Fakültesi Sürekli Tıp Eğitimi Etkinlikleri, Sempozyum Dizisi No: 63 İstanbul: Aksu Basım Yayın, 2008: 79-80.

21. Özbek MN, Topaloğlu AK. Cocukluk çağında obezite. Beslenme ve Metabolizma Hastalıkları. Türkiye Klinikleri Pediatrik Bilimler 2007; 3: 47-50.

22. Özcebe $\mathrm{H}$. Adolesanlar ve riskli davranışlar. (PDF)

23. Zaybak A, Fadıloğlu Ç. Üniversite öğrencilerinin sağlığı geliştirme davranışı ve bu davranışı etkileyen etmenlerin belirlenmesi. Ege Üniversitesi Hemşirelik Yüksekokulu Dergisi 2004; 20: 71-95.

24. Alikașșifoğlu M, Ercan O. Ergenlerde riskli davranıșlar. Türk Ped Arş 2009; 44: 1-6. (Abstract) / (Full Text) / (PDF)

25. Ardıç A. Adolesanların Sağlıkı Yașam Biçimi Davranıșları. İstanbul: İstanbul Üniversitesi Sağlık Bilimleri Enstitüsü Yüksek Lisans Tezi, 2008.

26. Hacıalioğlu N. Adolesan sağlığı. İçinde: Erici B. ed. Halk Sağlığı Hemșireliği, Ankara: Fırat Matbaacılık, 2009: 104-17.

27. Camcıoğlu Y. Adolesan çağında yeni bir aşı; human papillomavirüs aşısı. İçinde: Ercan O ed (s). Adolesan Sağlığı II. ï̈ Cerrahpaşa Tıp Fakültesi Sürekli Tıp Eğitimi Etkinlikleri, Sempozyum Dizisi No: 63 İstanbul: Aksu Basım Yayın, 2008: 117-24.

28. Çavușoğlu H. Çocuk Sağlığı Hemșireliği. Cild 1, Ankara: Hürbilek Matbaası, 2008: 51-67. 